http://jmscr.igmpublication.org/home/

ISSN (e)-2347-176x ISSN (p) 2455-0450

crossref DOI: https://dx.doi.org/10.18535/jmscr/v7i7.64

Journal Of Medical Science And Clinical Research

IGM Publication

An Official Publication of IGM Publication

\title{
Study of Postoperative Complications of Mesh Repair in Ventral Hernia in Obese and non Obese Patients
}

Authors

\section{Dr D. Nagarajan MS. ${ }^{1}$, Dr Mathan Sankar. S MS ${ }^{2 *}$, Dr T. Ajay Kumar ${ }^{3}$}

${ }^{1}$ Professor \& HOD, Dept of General Surgery, Chettinad Hospital \& Research Institute (CHRI), Chennai,

Tamil Nadu, India

${ }^{2}$ Assistant Professor, Dept of General Surgery, Chettinad Hospital \& Research Institute (CHRI),

Chennai, Tamil Nadu, India

${ }^{3}$ MS Post Graduate Resident, Dept of General Surgery,Chettinad Hospital \& Research Institute (CHRI),

Chennai, TamilNadu, India

*Corresponding Author

Dr Mathan Sankar. S MS.

\begin{abstract}
Aim and Objectives: To analyse the short-term post operative complications following repair of ventral hernia using two different materials for mesh fixation among obese and non-obese patients and to identify the risk factor for the complications between obese and non-obese cases.

Materials and Methods: This Prospective, randomized, comparative study was conducted in the Department of Surgery, in Chettinad Hospital and Research Institute. Patients scheduled for umbilical hernias and previous midline incision who met the inclusion criteria. 40 subjects from the sample are divided into four groups of ten by means of a computer generated randomization code.The data collection for the study was done over a period in the year of 2017-2018. All went hernia repair based following suture material in two different groups. Non - obese - Group A1 - Vicryl Group A2 - Prolene and in Obese group - Group B1 - Vicryl, Group B2 - Prolene.

Results: This study shows most common age group distribution is less than 50 yrs (60\%) with male preponderance. The complication seroma is (15\%) more common in Obese Vicryl patients, sinus formation $(12.5 \%)$ seen in obese prolene patients, Chronic pain is $(22.5 \%)$ more common in both obese and non obese prolene patients.

Conclusion: Obesity plays a major role in Ventral hernia and its complication shows vast variation between Obese and non-obese patients. Among the two different suture materials are Vicryl and prolene, vicryl shows more complications especially in obese patients than prolene. . In future this study helpful in reduce the risk of postoperative complications and recurrence of hernia among the patients.

Keywords: Hernia, Prolene, Vicryl, Obese, Seroma.
\end{abstract}

\section{Introduction}

The ventral hernia is the penetration of intra abdominal contents via an opening of weak areas within abdominal wall muscles caused by partially cured surgical incisions. Due to incisions must made at the mid line of anterior abdominal wall these incisional hernias are called ventral hernias $(1,2)$. Various studies stated that incisional hernia occurs in three percent to 20 percent more in laparotomy incisions. Which might happen with a 
occurrence as much as twenty three percentage while the abdominal incision is complex with a wound contamination ${ }^{(3,4)}$.

In this clinical study post-operative complications in obese and non-obese patients based on BMI after reconstruction surgery of anterior hernia using mesh has been considered. This study helps to recognize the complications, the risk factors related with the occurrence of these complications in obese and non-obese individuals. Thus it will help to make out the post operative complications at an earlier stage there by reducing the morbidity i.e recurrence of hernia.

\section{Aim of the Study}

The main aim of the study is:

1. To study the short-term post operative complications following repair of ventral hernia using two different materials for mesh fixation among obese and non-obese patients.

2. To identify the risk factor for the complications between obese and non-obese cases.

Along with this study, history and etiology of ventral hernia, age and sex incidence, clinical presentation, risk factors will be discussed.

\section{Materials and Methods}

Study Site: This study was conducted in the Department of Surgery, in Chettinad Hospital andResearch Institute.

Study Population: Patients scheduled for umbilical hernias and previous midline incision who met the inclusion exclusion criteria.

\section{Study Design: Prospective, randomized,} comparative study.

Sample Size: The sample size was calculated based on purposive sampling method. Average, standard deviation with an alpha error of 0.05 and a power of $90 \%$. A total of 10 patients per group was necessary to demonstrate statistical significance. Therefore, we assigned 20 patients to each group for a total of four groups.

Randomization Method 40 subjects from the sample are divided into four groups of ten by means of a computer generated randomization code

Study Duration: The data collection for the study was done over a period in the year of 2017-2018. Inclusion Criteria: Patients with- Upper/Lower midline

Exclusion Criteria: Recurrent incisional hernia, Patients presenting with complications such as wound infection, chronic respiratory tract infection, chronic constipation and abdominal distention due to ascites, Patients with other factors which affect wound healing like glucocorticoid therapy and patients on immunosuppressive drugs.

Study Methodology: After obtaining approval from Institutional Human Ethical Committee and written informed consent from the patients, forty patients scheduled for umbilical hernias and previous midline incision in the Department of Surgery at Chettinad Hospital and Research Institute were included in the study. Selected forty patients was randomly divided into two main groups (20 patients in each group) based on their body mass index using a computer generated randomization code. And those two groups further subdivided into two groups (10 patients in each group) based on the suture material used. Selection of patients was done by purposive sampling method.

1. Non - obese - Group A 1- Vicryl

Group B 1-Prolene

\section{2. $\quad$ Obese - Group A2 - Vicryl \\ Group B2- Prolene}

All patients underwent detailed clinical examination and relevant investigations. Pre operative anaesthesia fitness was obtained and posted for surgery. In all the sample population On-Lay mesh technique was utilized. Both the study groups were closely monitored for immediate post-operative complications till date of discharge and then followed up on a monthly basis for a period of 6 months.After administration of anaesthesia, parts painted and 
draped. Incision made according to the Ventral hernia and incision deepened in layers. Hernial sac identified and contents pushed in after opening the sac. Remnant sac transfixed and ligated. The defect in the myofascial layer closed using the selected suture material for the particular group. Mesh placed over the myofascial plane (On-lay mesh) and fixed using the selected suture material. In all patients skin closed using ethilon.

Statistical Analysis: Descriptive statistics and frequencies were used to summarize the statistics, including demographics, general health status and complications were used to define the study population. Results were considered significant if the observed $\mathrm{P}$ level were less than 0.05. All statistical analyses were performed by SPSS 21 .

\section{Results}

\section{Demographic and clinical characteristics of study subjects}

The demographic and clinical characteristics of postoperative complications of mesh repair in ventral hernia in obese and non-obese individuals are summarized and explained as follows. A total of 40 patients were included in this study, divided into two main groups and sub-groups based on the mesh material respectively. The below table 1 explains male and female subjects among the two groups in which in Group-B1 vicryl had only males and other groups had both males and females.

Table 1: Total males and females among the study groups

\begin{tabular}{|l|c|c|}
\hline Sex & Male & Female \\
\hline Group-A1 Vicryl & 03 & 07 \\
\hline Group-A2 Prolene & 06 & 04 \\
\hline Group-B1 Vicryl & 10 & 00 \\
\hline Group-B2 Prolene & 08 & 02 \\
\hline
\end{tabular}

Likewise, the patients were grouped based on their age below 50 years, above 51 years among the study subjects which revealed that Group-A1 with Vicryl and Group-A2 with Prolene mesh had $70 \%$ of males who were aged below 50 among the total patients. They are illustrated in figure 1

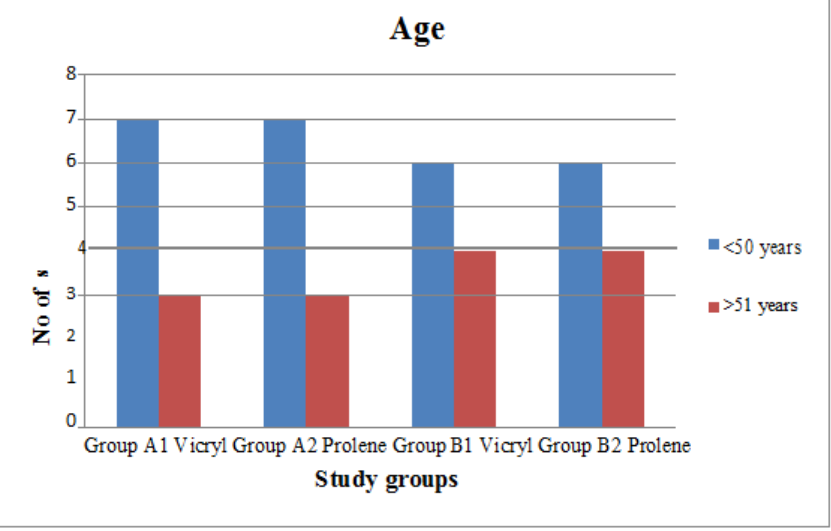

Figure 1: Bar chart illustrating age among the study groups

\section{Complication among the study groups 3.1 Seroma}

The other major complications associated with hernia were studied such as Seroma, Wound Infection, Sinus Formation, Early Recurrence, Chronic Pain, and Hernia were documented from all the collected subjects.

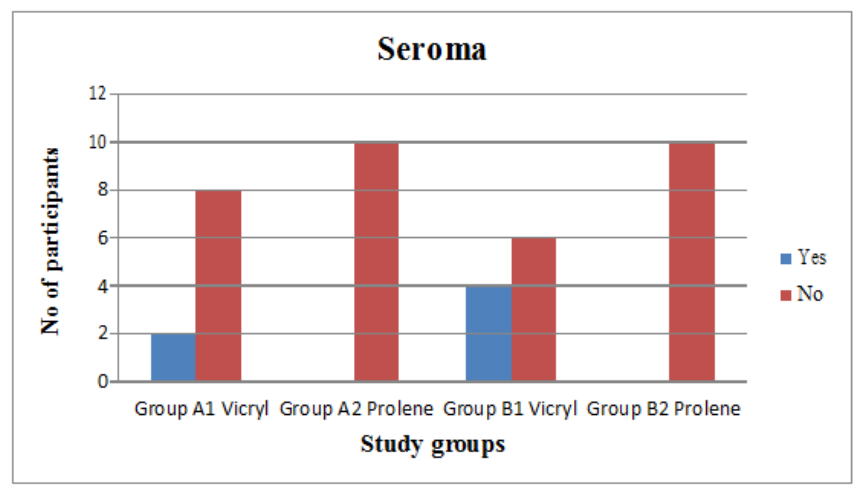

Figure 2: Bar chart illustrating Seroma status among the study groups

The seroma status was analyzed among the two groups which revealed us that it was high in Group-B1 having the vicryl mesh followed by Group-A1 vicryl mesh which is illustrated in figure 2

\subsection{Sinus formation among the study groups}

The sinus formation was analyzed among the two groups which revealed us that it was observed in Group-B2 having the Prolene mesh and in other groups it was not observed which is demonstrated in figure 3 


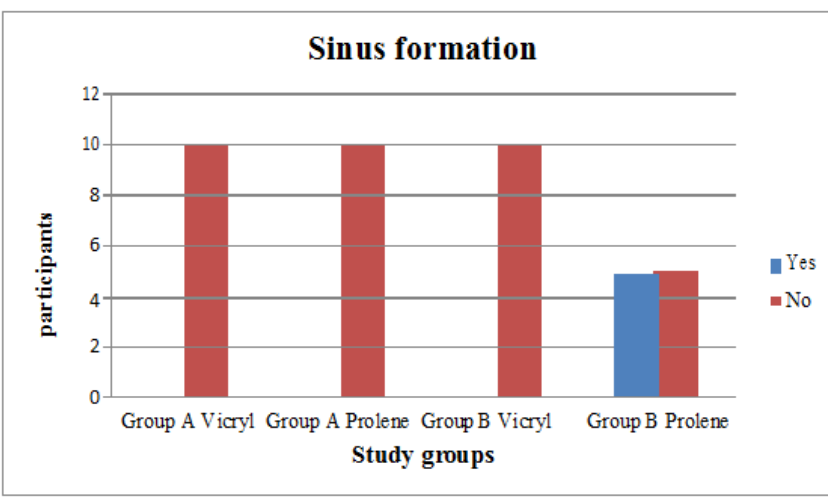

Figure 3: Sinus formation among the study groups

\subsection{Chronic pain among the study groups}

The chronic pain among the study participants was analyzed between the two groups which revealed us that it was observed in Group-A2 having the Prolene mesh followed by Group-B2 Prolene mesh and in other groups it was not observed which is showed in table 2 .

Table 2: Chronic pain among the study groups

\begin{tabular}{|c|c|c|}
\hline Chronic Pain & Yes & No \\
\hline Group-A1 Vicryl & 0 & 10 \\
\hline Group-A2 Prolene & 5 & 5 \\
\hline Group-B1 Vicryl & 0 & 10 \\
\hline Group-B2 Prolene & 4 & 6 \\
\hline
\end{tabular}

\section{Body Mass Index Assessment among the study groups}

The mean BMI of the study groups were calculated and compared with published values of the IAP guidelines (2015) and are illustrated in table 3. The BMI in Group-B (B1 Vicryl and B2 Prolene) were higher than the Group-A (A1 Vicryl and A2 Prolene) respectively.

Table 3 Body Mass Index among the study groups

\begin{tabular}{|c|c|}
\hline Study Groups & BMI \\
& Mean \pm SD \\
\hline $\begin{array}{c}\text { Group-A1 Vicryl } \\
2\end{array}$ & $22.89 \pm 1.18$ \\
\hline Group-A2 Prolene & $23.73 \pm 0.74$ \\
\hline Group-B1 Vicryl & $28.12 \pm 1.06$ \\
\hline Group-B2 Prolene & $27.68 \pm 1.45$ \\
\hline
\end{tabular}

5. Comparison of Hernia (umbilical hernia, incisional hernia) types among the study groups

The comparison of Hernia with study groups was carried out for the collected samples, which revealed us equal proportion of hernia (umbilical, incisional) was observed in Group-A1 Vicryl followed by other groups respectively figure 4 .

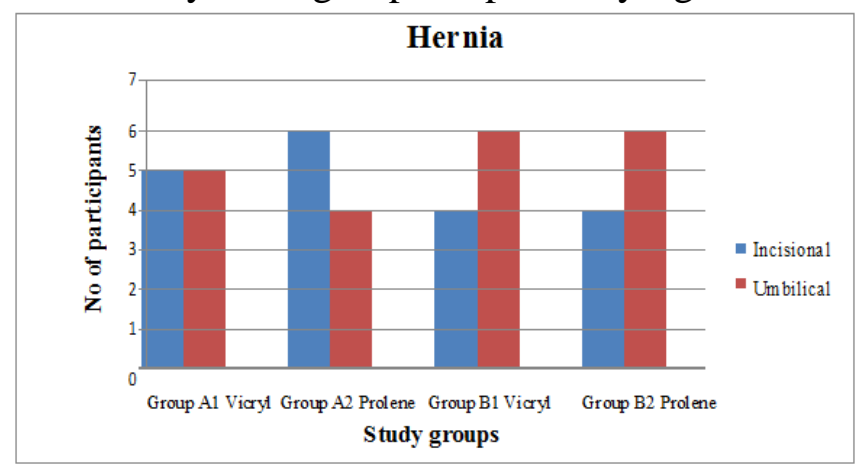

Figure 4: Bar chart illustrating Hernia types among the study groups

\section{BMI range among the study groups}

The BMI was measured according to the standard scales of measurement, they can be classified as Underweight, Normal weight, Overweight and Obese, the results from our study revealed GroupA (A1 \& A2) subjects were classified under normal weight and Group-B (B1\&B2) subjects were classified as Overweight which are illustrated in figure 5 .

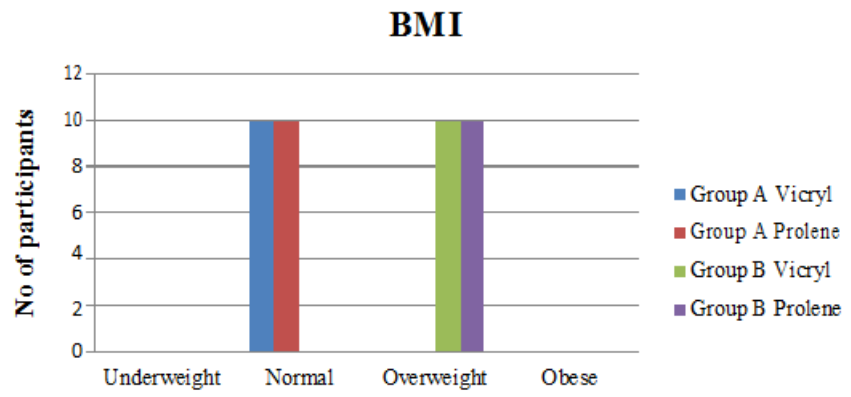

Figure 5: Bar chart illustrating BMI range among the study groups

7 Comparison of Hernia (umbilical hernia, incisional hernia) types among males and females

The comparison of Hernia with study groups among the males and females was carried out for the collected samples, which revealed us mixed 
proportion were observed in the study groups which are shown in the figure 6 .

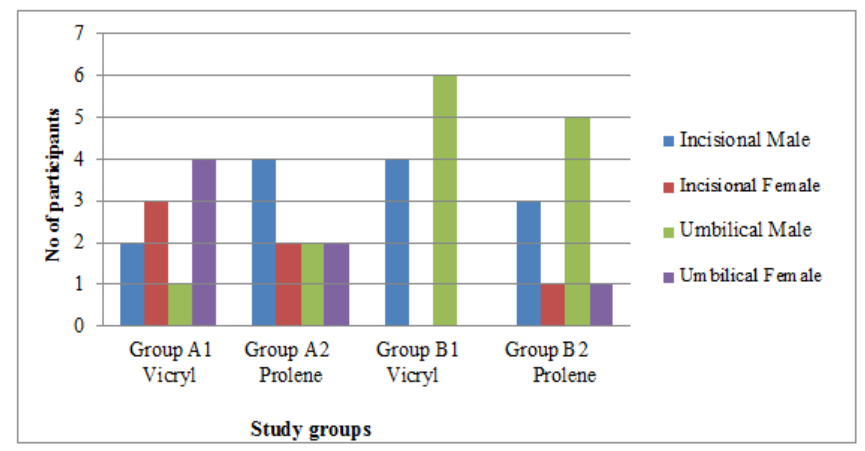

Figure 6: Bar chart illustrating Hernia types among males and females

\section{Complications percentage among non-obese study subjects}

The other complications among non-obese subjects were expressed in percentage in table 4, in group-A (A1 and A2) the complications were $20 \%$ for Seroma, and $50 \%$ for chronic pain with Vicryl mesh respectively.

Table 4 Complications percentage among the study groups

\begin{tabular}{|l|c|c|c|}
\hline $\begin{array}{l}\text { Group } \\
\text { Non Obese }\end{array}$ & $\begin{array}{c}\text { Seroma } \\
(\%)\end{array}$ & $\begin{array}{c}\text { Chronic } \\
\text { Pain }\end{array}$ & P-value \\
$(\mathbf{\%})$ & \\
\hline $\begin{array}{l}\text { Group- A } \\
\text { (A1 Vicryl, }\end{array}$ & 20 & 50 & 0.0494 \\
A2 Prolene) & & & \\
\hline
\end{tabular}

\section{Complications percentage among obese study subjects}

The other complications among obese subjects were expressed in percentage in table 5, in groupB (B1 and B2) the complications were $40 \%$ for Seroma, $50 \%$ for Sinus formation and $40 \%$ for chronic pain respectively.

Table 5 Complications percentage among the study groups

\begin{tabular}{|c|c|c|c|c|}
\hline $\begin{array}{c}\text { Group } \\
\text { Obese }\end{array}$ & $\begin{array}{c}\text { Seroma } \\
(\%)\end{array}$ & $\begin{array}{c}\text { Sinus } \\
\text { Formation } \\
(\%)\end{array}$ & $\begin{array}{c}\text { Chronic } \\
\text { Pain } \\
(\%)\end{array}$ & P-value \\
\hline $\begin{array}{c}\text { Group-B } \\
\text { (B1 Vicryl, } \\
\text { B2 Prolene) }\end{array}$ & 40 & 50 & 40 & 0.0449 \\
\hline
\end{tabular}

\section{Complications percentage based on mesh}

The complications based on the mesh used in the subjects were expressed in percentage in table 6, in group-A, B respectively.

Table 6 Complications percentage among the study groups

\begin{tabular}{c|c|c|c|c|}
\hline Groups & $\begin{array}{c}\text { Seroma } \\
(\mathbf{\% )}\end{array}$ & $\begin{array}{c}\text { Formation } \\
(\mathbf{\%})\end{array}$ & $\begin{array}{c}\text { Chronic } \\
\text { Pain } \\
\mathbf{( \% )}\end{array}$ & P-value \\
\hline $\begin{array}{c}\text { Group-A1, B1 } \\
\text { Vicryl }\end{array}$ & 30 & 0 & 0 & \multirow{2}{*}{0.0561} \\
\cline { 1 - 3 } $\begin{array}{c}\text { Group-A2, B2 } \\
\text { Prolene }\end{array}$ & 0 & 25 & 40 & \\
\hline
\end{tabular}

The above table illustrates the complications based on the mesh on both the groups, which revealed us that chronic pain was highly observed among the study participants using prolene mesh respectively

\section{Discussion}

The morbidly obese patients might be susceptible to develop hernias of wall of abdomen with the possible complications of small intestine obstacles and followed by some other co-morbidity.

This study of included male: female-27:13 respectively, from the collected data it can be inferred that, higher number of males were included in this current study. Among the total study participants, highest numbers were from less than 50 years age. Likewise 20 patients were having normal weight and 20 patients were grouped under over weight, which is nearly $50 \%$ for both the groups. When comparing the results with other countries such as United States, overweight / obesity was found to be correlated with higher risk of other clinical issues.

Nearly, 63\%, 55\% male and female aged above 25 years or older are tend to be obese. Several casestudies have documented and recommended that a losing of weight might help to develop the technical conditions of the intervention and helps to decrease the possible re-occurrence rate, however it might not change the perioperative complications risk ${ }^{(9)}$. However, weight loss and the time required for substantial weight loss is need to be balanced with the clinical symptoms for the hernia repair and also for the bariatric 
surgery. It is well documented that obese / overweight subjects are more likely to have comorbid medical complications, which leads to their peri-operative risk. The surgical treatment gets complicated because of obesity by increasing the risk of surgical events, such as the blood transfusion, wound healing problems, readmissions, nosocomial infections, abscess formation and infections at the surgical sites ${ }^{(10)}$.

Further, the obese subjects have high incidence of insulin resistance, diabetes complications, poor glycemic control, which are previously documented to increase the postoperative complications risk $^{(11)}$. In this current study, we have observed significant differences in complications between Group-A and Group-B; we noticed a trend towards increase in complications associated with obesity in our study ${ }^{(12)}$. The choice and selection of mesh is important issue in these types of surgical procedures ${ }^{(13)}$. The usage of bioprosthetic mesh has

been previously found to be associated with a less incidence of mesh-related infections, enterocutaneous fistulae and adhesion; low rate of infection, exposure of mesh leading to explantation, wound complications and reconstruction failure, but they have similar hernia recurrence rates when comparing with synthetic mesh and they are more expensive ${ }^{(14)}$.

Our study can be considered with some limitations such as; first the sample-size of this study is relatively small and 40 samples were only analyzed, with two groups such as obese and nonobese subjects. In conclusion from this study, more studies on this hernia with obesity are to be warranted and, the effect of preoperative weight loss among bariatric surgery, obese patients, should be further extensively investigated as a preventive measure to reduce the risk of postoperative complications and recurrence of hernia among the patients.

The study population is less but in this also it shows the dramatic changes in all the parameters.Obesity plays a major role in Ventral hernia and its complication shows vast variation between Obese and non-obese patients. Gender play a vital role in this study. In obese patients males were more than females so it may be one of the factor for more complications. Among the two different suture materials are Vicryl and prolene, vicryl shows more complications especially in obese patients than prolene. Complications associated with hernia were studied such as Seroma, Wound Infection, Early Recurrence, Chronic Pain were seen more in vicryl group patients with obese than other. Sinus Formation occurs more in prolene patients with obese than other.

\section{Conclusion}

From this study we concluded that Obesity plays a major role in Ventral hernia and its complication shows vast variation between Obese and nonobese patients. Among the two different suture materials are Vicryl and prolene, vicryl shows more complications especially in obese patients than prolene. Sinus formation more in prolene.

More studies on this hernia with obesity are to be warranted and the effect of preoperative weight loss among bariatric surgery, obese patients, should be further extensively investigated as a preventive measure. In future this study helpful in reduce the risk of postoperative complications and recurrence of hernia among the patients.

\section{References}

1. Breuing K, Butler CE, Ferzoco S, Franz M, Hultman CS, Kilbridge JF, et al. Incisional ventral hernias: Review of the literature and recommendations regarding the grading and technique of repair. Surgery. 2010.

2. Eriksen JR, Gögenur I, Rosenberg J. Choice of mesh for laparoscopic ventral hernia repair. Hernia. 2007.

3. Fink C, Baumann P, Wente MN, Knebel $\mathrm{P}$, Bruckner $\mathrm{T}$, Ulrich $\mathrm{A}$, et al. Incisional hernia rate 3 years after midline laparotomy. Br J Surg. 2014; 
4. Sugerman HJ, Kellum JM, Reines HD, DeMaria EJ, Newsome HH, Lowry JW. Greater risk of incisional hernia with morbidly obese than steroid-dependent patients and low recurrence with prefascial polypropylene mesh. Am J Surg. 1996;

5. Le Huu Nho R, Mege D, Ouaïssi M, Sielezneff I, Sastre B. Incidence and prevention of ventral incisional hernia. $\mathrm{J}$ Visc Surg. 2012;

6. Lau H, Fang C, Yuen WK, Patil NG. Risk factors for inguinal hernia in adult males: A case-control study. Surgery. 2007;

7. Ruhl CE, Everhart JE. Risk factors for inguinal hernia among adults in the US population. Am J Epidemiol. 2007;

8. Abo-Ryia MH, El-Khadrawy OH, AbdAllah HS. Prophylactic preperitoneal mesh placement in open bariatric surgery: A guard against incisional hernia development. Obes Surg. 2013;

9. Bringman S, Conze J, Cuccurullo D, Deprest J, Junge K, Klosterhalfen B, Parra-Davila E, Ramshaw B, Schumpelick V. Hernia repair: the search for ideal meshes. Hernia. 2010 Feb 1;14(1):81-7.

10. Curet MJ. Special problems in laparoscopic surgery: previous abdominal surgery, obesity, and pregnancy. Surgical Clinics of North America. 2000 Aug 1;80(4):1093-110.

11. Matsuzawa Y. Adiponectin: a key player in obesity related disorders. Current pharmaceutical design. 2010 Jun 1;16(17):1896-901.

12. Kehlet H, Wilmore DW. Multimodal strategies to improve surgical outcome. The American journal of surgery. 2002 Jun 1;183(6):630-41
13. Cavallaro A, Menzo EL, Di Vita M, Zanghì A, Cavallaro V, Veroux PF, Cappellani A. Use of biological meshes for abdominal wall reconstruction in highly contaminated fields. World journal of gastroenterology: WJG. 2010 Apr 21;16(15):1928.

14. Breuing K, Butler CE, Ferzoco S, Franz M, Hultman CS, Kilbridge JF, Rosen M, Silverman RP, Vargo D, Ventral Hernia Working Group. Incisional ventral hernias: review of the literature and recommendations regarding the grading and technique of repair. Surgery. 2010 Sep 1;148(3):544-58.

15. Matthews RD, Anthony T, Kim LT, Wang J, Fitzgibbons Jr RJ, Giobbie-Hurder A, Reda DJ, Itani KM, Neumayer LA, Veterans Affairs Cooperative 456 Studies Program Investigators. Factors associated with postoperative complications and hernia recurrence for patients undergoing inguinal hernia repair: a report from the VA Cooperative Hernia Study Group. The American Journal of Surgery. 2007 Nov 1;194(5):611-7.

16. Nelson JA, Fischer JP, Cleveland EC, Wink JD, Serletti JM, Kovach III SJ. Abdominal wall reconstruction in the obese: an assessment of complications from the National Surgical Quality Improvement Program datasets. The American Journal of Surgery. 2014 Apr 1;207(4):467-75. 